\title{
Informing relatives at risk of inherited cardiac conditions: experiences and attitudes of healthcare professionals and counselees
}

\author{
Lieke M. van den Heuvel ${ }^{1} \cdot$ Mette J. Huisinga ${ }^{1} \cdot$ Yvonne M. Hoedemaekers $^{2} \cdot$ Annette F. Baas $^{3} \cdot$ Mirjam Plantinga $^{2}$. \\ Lidewij Henneman $^{4} \cdot$ J. Peter van Tintelen ${ }^{1,3} \cdot$ Ellen M. A. Smets $^{5} \cdot$ Imke Christiaans $^{1,2}$
}

Received: 10 January 2019 / Revised: 2 April 2019 / Accepted: 16 April 2019 / Published online: 3 May 2019

(c) European Society of Human Genetics 2019

\begin{abstract}
Inherited cardiac conditions (ICCs) can lead to sudden cardiac death at young age, even without previous symptoms, yet often remain undetected. To prevent sudden cardiac death, cardiac monitoring and/or predictive DNA testing is advised for at-risk relatives. Probands in whom a causal variant is detected are asked to inform their relatives about the possibility of testing, often supported by a family letter. This qualitative study investigates experiences with and attitudes toward this family-mediated approach in ICCs and explores whether and how improvements can be made. Two online focus groups were conducted with 28 healthcare professionals (HCPs) from various disciplines, as were 25 face-to-face semi-structured interviews with counselees (10 probands; 15 relatives). Data were analysed by two researchers independently using a thematic approach. Participants, both HCPs and counselees, preferred that probands inform relatives about genetic risks in ICCs, but both groups struggled with the dependency on and burden on probands to inform their relatives. To overcome this, HCPs do see a more active role for themselves in informing relatives, but prefer uniformity in procedures in order to maintain their workload. Counselees, on the other hand, prefer a tailored information provision strategy adjusted to family dynamics and the personality characteristics of relatives. In conclusion, although it is generally preferred that probands inform relatives themselves, a more active role of HCPs could be considered to overcome the dependency and burden on probands. Further research is needed to study how HCPs can engage more actively in informing at-risk relatives in current clinical genetic practise.
\end{abstract}

Supplementary information The online version of this article (https:// doi.org/10.1038/s41431-019-0410-9) contains supplementary material, which is available to authorized users.

Imke Christiaans

i.christiaans@amc.uva.nl

1 Department of Clinical Genetics, Amsterdam UMC, University of Amsterdam, Amsterdam, The Netherlands

2 Department of Genetics, University of Groningen, University Medical Centre Groningen, Groningen, The Netherlands

3 Department of Genetics, University Medical Centre Utrecht, University Utrecht, Utrecht, The Netherlands

4 Department of Clinical Genetics, Amsterdam UMC, Vrije Universiteit, Amsterdam, The Netherlands

5 Department of Medical Psychology, Amsterdam UMC, University of Amsterdam, Amsterdam, The Netherlands

\section{Introduction}

Inherited cardiac conditions (ICCs), including cardiomyopathies and primary arrhythmia syndromes, may manifest at any age and generally show an autosomal dominant inheritance pattern. People with a hereditary predisposition to the disease can remain asymptomatic, but may also manifest symptoms of severe heart failure and arrhythmias. ICCs may even result in sudden cardiac death at relatively young age. Preventive and treatment options for ICCs are available [1,2]. Therefore, when a likely pathogenic or pathogenic variant is identified in a proband, predictive DNA testing is advised to relatives at risk to investigate whether they also carry the variant and allow for cardiac evaluation and, if necessary, treatment [3, 4]. Relatives who do not inherit the genetic variant and their offspring have no increased risk of heart problems and do not need (further) cardiac evaluation [4].

Current clinical genetic practise relies on the proband to inform relatives at risk, an approach referred to as the 
family-mediated approach [5]. However, using this family-mediated approach, fewer than half of all relatives at risk of cardiomyopathies attend genetic counselling $[6,7]$. In primary arrhythmia syndromes, this percentage seems somewhat higher than in cardiomyopathies [7, 8]. This low uptake of genetic counselling might suggest that, beyond relatives who made a well-informed decision not to have predictive DNA testing, some relatives might still be insufficiently aware or unaware of their genetic risk and the possibility of predictive DNA testing, as indicated by genetic counsellors' reports of nondisclosure $[9,10]$.

It is therefore worth investigating whether the currently used family-mediated approach could be improved to increase relatives' risk awareness and enable more relatives to make a well-informed decision regarding predictive DNA testing. Indeed, some intervention studies focussing on supporting probands in informing relatives showed an increase in the number of relatives who attended genetic counselling [11, 12]. A more active role for healthcare professionals (HCPs) in informing relatives at risk has been suggested as well, with HCPs contacting relatives directly about their genetic risks [13-17]. Genetic counsellors seem to experience a feeling of responsibility to inform relatives at risk of inherited diseases, but currently struggle with how to act on this [18]. Studies on more active approaches suggest they increase uptake of genetic counselling and that relatives were satisfied with how they were informed with no harmful psychological consequences of a more active approach reported [13, 15, 16].

Previous research on informing relatives at risk has mainly been conducted in families at risk of hereditary types of cancer, Huntington's disease, and diseases with an autosomal recessive inheritance pattern. Insight into the attitudes and preferences of HCPs and counselees regarding the approach used to inform relatives at risk of ICCs is limited. Furthermore, attitudes regarding alternative approaches toward informing at-risk relatives are still underexplored. Therefore, this qualitative study aimed to explore the experiences with and attitudes toward the family-mediated approach of HCPs and counselees in a cardiogenetic patient population.

\section{Materials and methods}

\section{Design}

Two online focus groups with Dutch HCPs involved in the care for families with ICCs were conducted to promote lively discussions between HCPs and to explore different perspectives [19]. Instead of face-to-face focus groups, online focus groups were used to enable HCPs from all eight cardiogenetics clinics in the Netherlands to participate. For more in-depth exploration, face-to-face semi-structured interviews were conducted with probands and relatives counselled in cardiogenetics clinics of three Dutch university hospitals (Amsterdam UMC (location AMC), University Medical Centre Groningen (UMCG), and University Medical Centre Utrecht (UMCU)). Interviews were chosen here because counselees preferred to discuss personal situations only with the interviewer. All data were gathered between April and August 2017. Ethical clearance for the study was granted by the Medical Ethical Committee of Amsterdam UMC, location AMC (W17-075). All participants gave written informed consent for participating in this study.

\section{Participant recruitment}

HCPs, including cardiologists, clinical geneticists, genetic counsellors, and psychosocial workers specialized in cardiogenetics, at all eight university hospitals running cardiogenetics outpatient clinics in the Netherlands were invited to participate by e-mail. Probands who had received cardiogenetic counselling in the year prior to the study, and their relatives, were invited to participate by an information letter with a response card. Those indicating interest in study participation were contacted by telephone by the executing researcher $(\mathrm{LMvdH})$ to further explain the study and to make an appointment for the interviews. A monetary incentive (a gift card of 10 euros) was offered to thank participants for their participation.

\section{Data collection}

Focus groups with HCPs and interviews with counselees were conducted by the executing researcher, a psychologist $(\mathrm{LMvdH})$, who was not involved in patient care. Researchers with expertise in clinical genetics, health sciences, and psychology developed a semi-structured topic guide for both the focus groups with HCPs and the interviews with counselees, which was completed based on existing literature (see Supplementary materials S1 and S2) $[8,13,20-22]$.

\section{Focus groups with HCPs}

Focus groups were conducted using an online focus group tool (www.focusgroupit.com). Participants could log in with their own e-mail address and self-chosen password. Each participant received a unique username by e-mail, and the executing researcher was the only person who had access to these usernames.

The focus groups were organized asynchronously: over a two-and-a-half week period a statement was posted online 
each working day. Participants were asked to respond to the statements, as well as to each other's reactions. Participants could respond at their own convenience, yet were obliged to respond to each statement before the next statement became visible. LMvdH guided the focus groups by posting additional questions that clarified participants' responses or requested additional information. The semi-structured topic guide comprised the following topics: perception of the responsibility or duty to inform relatives at risk of ICCs; attitudes toward the family-mediated approach; opinions on other, more active, approaches and participant preferences (including a direct contact approach, which was explained during the focus groups); opinions on the content of the information provided to at-risk relatives; and perceived barriers in informing at-risk relatives and possible solutions to overcome these barriers.

\section{Interviews with counselees}

Interviews with counselees were conducted face-to-face. The semi-structured topic guide comprised the following topics: experiences with informing or with being informed about the ICC diagnosis and possibility of predictive DNA testing; opinions on the information received and the medium that was used; attitudes toward the approach used to inform relatives at risk and opinions regarding other possible approaches (including a direct contact approach, which was explained during the interview); opinions on the responsibility or duty to inform relatives at risk; and perception of barriers in informing at-risk relatives and possible solutions to overcome these barriers. On average, the interviews lasted $1 \mathrm{~h}$ ( $\min .36 \mathrm{~min}$, max. $85 \mathrm{~min}$ ). Interviews took place at counselees' homes or in a hospital in their neighbourhood, according to counselees' preferences. Interviews were audio-recorded and transcribed verbatim. Member checking of the interviews was performed by asking participants to assess whether a detailed summary of the interview corresponded with their experiences and attitudes. After 23 interviews, no new themes emerged, indicating that data saturation had been reached. Since the last two participants already indicated their interest in participating in the study, these participants were included in the study as well.

\section{Data analysis}

Transcripts of the focus groups and interviews were exported to the qualitative software program MAXQDA version 12 [23]. Initial coding analysis of each transcript based on the principles of thematic analysis of Braun and Clarke [24] was performed by $\mathrm{LMvdH}$ and $\mathrm{MJH}$ independently. The codes were organized into a coding framework, which was discussed by the two researchers and modified until they reached agreement. Main themes and subthemes were derived from the coding analysis. Subthemes emerged during the focus groups and interviews, and subsequently during analyses of the data. Differences in attitudes between HCPs, and patients and relatives were explored, as well as differences between HCPs' specialisms. The transcripts were repeatedly read to check whether the derived themes and subthemes were consistent with the data.

\section{Results}

\section{Research participants}

Table 1 shows the sociodemographic and clinical characteristics of the participants.

In total, 28 of the $50 \mathrm{HCPs}$ who were invited consented to participate in the online focus groups (response rate $56 \%)$, including clinical geneticists $(n=11)$, cardiologists $(n=9)$, genetic counsellors $(n=4)$, and psychosocial workers $(n=4)$. HCPs from each Dutch cardiogenetics clinic participated, and all HCPs had more than 6 years of experience. Two participants (a clinical geneticist and a psychosocial worker) dropped out during the first week of the focus group due to lack of time and illness, respectively. In total, 42 probands and 67 relatives who received genetic counselling and underwent genetic testing were asked to participate in this study. Interviews were conducted with 10 probands diagnosed with an ICC and a likely pathogenic or pathogenic variant (response rate $23.8 \%$ ): eight female and two male participants with mean age 59.6 (range 36-77). In the majority of probands, a cardiomyopathy was diagnosed. Fifteen first-degree relatives consented to participate in the interviews (10 carriers, 5 non-carriers; response rate 22.4\%): nine female and six male respondents with mean age 54.6 (range 29-71). Most relatives received genetic counselling for a cardiomyopathy diagnosed in their family, of whom eight relatives were identified as a carrier.

\section{Who should inform relatives at risk?}

Table 2 shows the main themes and subthemes identified, with exemplar quotations from counselees and HCPs regarding who should inform relatives at risk of ICCs.

\section{Responsibility}

In general, both HCPs and counselees believed that relatives should be informed about their risk of ICCs. The majority even considered this a moral obligation. Because of the availability of preventive and treatment options in ICCs, the moral obligation to inform relatives at risk was experienced 
Table 1 Characteristics of participants in focus groups (HCPs) and interviews (counselees)

\begin{tabular}{|c|c|c|}
\hline HCPs (focus groups) & $N(\%)$ & \\
\hline \multicolumn{3}{|l|}{ Gender } \\
\hline Male & \multicolumn{2}{|l|}{$12(42.9)$} \\
\hline Female & \multicolumn{2}{|l|}{$16(57.1)$} \\
\hline \multicolumn{3}{|l|}{ Profession } \\
\hline Clinical geneticist & \multicolumn{2}{|l|}{$11(39.3)$} \\
\hline Cardiologist & \multicolumn{2}{|l|}{$9(32.1)$} \\
\hline Genetic counsellor & \multicolumn{2}{|l|}{$4(14.3)$} \\
\hline Psychosocial worker & \multicolumn{2}{|l|}{$4(14.3)$} \\
\hline \multicolumn{3}{|l|}{ Years of work experience } \\
\hline $6-10$ years & \multicolumn{2}{|l|}{$9(32.1)$} \\
\hline $11-20$ years & \multicolumn{2}{|l|}{$10(35.7)$} \\
\hline $21-30$ years & \multicolumn{2}{|l|}{$9(32.1)$} \\
\hline Counselees (interviews) & Probands $N(\%)$ & Relatives $N(\%)$ \\
\hline \multicolumn{3}{|l|}{ Gender } \\
\hline Male & $2(20.0)$ & $6(40.0)$ \\
\hline Female & $8(80.0)$ & $9(60.0)$ \\
\hline Married or living with partner & $6(60.0)$ & $12(80.0)$ \\
\hline Parenthood & $9(90.0)$ & $11(73.3)$ \\
\hline \multicolumn{3}{|l|}{ Education level $^{\mathrm{a}}$} \\
\hline Low & $2(20.0)$ & $1(6.7)$ \\
\hline Moderate & $6(60.0)$ & $5(33.3)$ \\
\hline High & $20(20.0)$ & $8(53.3)$ \\
\hline Unknown & $0(0.0)$ & $1(6.7)$ \\
\hline \multicolumn{3}{|l|}{ ICC } \\
\hline Cardiomyopathy & $7(70)$ & $\begin{array}{l}12(80.0) ; \\
(8 \text { carriers, } \\
4 \text { non-carriers })\end{array}$ \\
\hline $\begin{array}{l}\text { Primary arrhythmia } \\
\text { syndromes }\end{array}$ & $2(20)$ & $\begin{array}{l}2(13.3) ; \\
(2 \text { carriers, } \\
0 \text { non-carriers })\end{array}$ \\
\hline $\begin{array}{l}\text { Familial } \\
\text { hypercholesterolaemia }\end{array}$ & $1(10)$ & $\begin{array}{l}1 \text { (6.7); (0 carriers, } \\
1 \text { non-carrier) }\end{array}$ \\
\hline
\end{tabular}

HCPs healthcare professionals, ICC inherited cardiac condition

a'Education level: [1] Low-elementary school, lower level of secondary school, lower vocational training; [2] Medium-higher level of secondary school, intermediate vocational training; and [3] High—-higher vocational training university

as greater in ICCs than in hereditary diseases for which there are no preventive or treatment options such as Huntington's disease (Table 2, quote 1.1). In addition, some counselees mentioned that not informing relatives would mean relatives have no choice of their own to take preventive measures, and it was therefore considered to be wrong. One proband anticipated feeling serious regret if relatives developed an ICC or died suddenly and he had not informed them, thereby hampering his relatives' ability to make their own decisions (Table 2, quote 1.2).
The consensus on the moral obligation to inform relatives between HCPs and counselees brings up the question of whose responsibility it is to inform. Generally, counselees felt responsible for informing their relatives themselves, because this felt like a logical and good thing to do (Table 2, quote 1.3). Many HCPs also believed that, ideally, probands should inform at-risk relatives. A psychosocial worker mentioned that probands should ideally feel responsible for informing relatives at risk, but that this responsibility cannot be imposed, i.e., probands who do not feel responsible cannot be made responsible (Table 2, quote 1.4).

Some participants believed that HCPs (also) have a responsibility in informing relatives (Table 2, quote 1.5). Different attitudes were observed regarding the extent to which HCPs are responsible. HCPs generally felt a responsibility to educate probands about the importance of informing relatives during pre- and post-test counselling and to motivate them to do this (Table 2, quote 1.6). In addition, many participants, both HCPs and counselees, believed that active support should be offered to counselees in informing their relatives whenever needed. Some of the participants believed this active support should encompass directly informing relatives by HCPs. Some were of the opinion that the HCP has the responsibility to inform only when the proband cannot or will not inform at-risk relatives (Table 2, quote 1.7). Several HCPs mentioned that families and HCPs have a shared responsibility to inform relatives (Table 2, quote 1.8).

\section{Attitudes regarding the approach used to inform relatives at risk}

Family-mediated approach The majority of study participants believed that the family-mediated approach works quite well, but only when there are close family bonds. Many participants mentioned the proband knows his or her relatives best, which was considered an advantage. Some probands believed that when they themselves inform relatives at risk, they could also share their experiences with genetic testing and with living with such a disease. Therefore, relatives can take this information into account when deciding on predictive DNA testing (Table 2, quote 2.1).

Many participants, however, also saw disadvantages in the family-mediated approach. It was mentioned that not all relatives were informed, and that the information would not be conveyed correctly (Table 2, quote 2.2). Some probands additionally reported that it remained unclear at times, which relatives were at risk and should be informed. In addition, it could be burdensome for counselees to inform relatives, which was primarily mentioned by probands in contrast to relatives. Some probands mentioned a practical burden, because there were many relatives to inform and 
Table 2 Themes and illustrative quotes from counselees and HCPs regarding who should inform relatives at risk of inherited cardiac conditions

\begin{tabular}{lll}
\hline Themes and subthemes & No. Participant Quotes \\
\hline
\end{tabular}

Responsibility

Responsibility

$1.1 \quad \mathrm{HCPs}$

1.2 Counselees

Responsibility proband

1.3 Counselees

$1.4 \quad \mathrm{HCPs}$

Responsibility HCP

1.5 Counselees

$1.6 \mathrm{HCPs}$

Shared responsibility

$1.7 \quad$ Counselees

$1.8 \quad \mathrm{HCPs}$

Approach used to inform at-risk relatives Family-mediated approach $2.1 \quad$ Counselees

$2.2 \mathrm{HCPs}$

2.3 Counselees aren't." (H12FG2, genetic counsellor, female)

"There is some sort of moral duty to warn. This moral duty is larger in case of a relatively high risk on sudden cardiac death, and when preventive interventions to prevent this [sudden cardiac death] are available." (H7FG1, clinical geneticist, male)

"Well I would find it frustrating if another event happened and, darn it, people said, 'I didn't know anything about it.' I would blame myself for that, because you have the information, you know that it's in the family. People can decide for themselves what to do with the information, but they need to know it." (U5FL, proband, male, 67 years)

"Well, as it can turn out to be a life threatening situation. That something really bad can happen, and definitely if you know what the consequences can be, I think that you need to get over yourself and that you need to share it." (A13FL, relative, male, 56 years)

"I can believe it is the responsibility of the proband, but improvement can only be gained if the proband also feels responsible." (H14FG2, psychosocial worker, female).

"Yeah, I do believe that [the HCP is responsible as well], because why would one be informed and the other not? It often concerns a matter of life and death. So I don't think it is complicated, I believe that everyone should be informed. And of relatives who decide not to participate [to not undergo predictive DNA testing], children should be informed." (U5IP, proband, female, 53 years)

"This [the responsibility of the healthcare provider] also depends on the disorder and the patient's point-of-view. The doctor definitely should do everything to convince the patient of the importance of family screening and the need to get it started." (H3FG1, cardiologist, male)

"If eh.. patients say eh.. 'well, I won't cooperate and inform my relatives', then I think that they [HCPs] have the duty and the responsibility to provide some information." (U1IP, proband, female, 60 years)

"We can't make anything mandatory. It is the counsellor's job to explain the situation well enough that the counselee understands that their cooperation is wanted in informing their relatives. Then together you can find the right manner to make this happen." (H11FG2, genetic counsellor, female)

"Look, I can explain [to relatives] what I have experienced all this time, both what I have felt and what I haven't. Why I had the surgeries and all the other things..." (U19IP, proband, female, 78 years)

"Personally, I think it [the approach to inform at-risk relatives] often does not work well enough. From previous experiences we know that patients often insufficiently understood who [which relatives] should be informed, for example that children are informed but brothers and sisters

irst, my father was like - and that's maybe not totally fair or justified - struggling with the feeling of maybe not informing us [children]. Only because my aunt 'accidently' told us, I knew that my father thought about not telling us.... He [my father] thought that if we would know there was a possibility to have it [be a carrier], then we also had to make a decision about it, 'yes' or 'no' [to test or not to test]." (U13FL, relative, male, 29 years)

2.4 HCPs "In most cases it seems to go well, even though we probably aren't aware of a lot of what happens behind the scenes. We're dependent on what the proband tells us, but we don't know to what extent relatives really were informed or if the information provided (in addition to the family letter) was correct." (H17FG2, psychosocial worker, female)

Direct approach

2.5 Counselees

"Yes, but I personally think that if my parents would have had the same reaction, then [the cascade screening process] would be shut down immediately. I think that the information just... I don't know if it's allowed for privacy reasons, but that it should go to the whole family in any case." (G4FL, relative, female, 39 years)

2.6 HCPs "I think that if health is at stake it seems to me that you can discuss approaching [family members] directly." (H11FG1, genetic counsellor, female)

2.7 Counselees "Well, I think it [direct contact by HCPs] would scare the socks of them. Yes, I do think that. Yeah, because no one right... - I don't know how their mother is doing, my aunt. No, I don't know anything about her health, whether she has any cardiac complaints, I don't know that. I don't even know if she is still alive, so that makes it very complicated." (G1IP, proband, female, 64 years) 
Table 2 (continued)

\begin{tabular}{|c|c|c|c|}
\hline Themes and subthemes & No. & Participant & Quotes \\
\hline \multirow{5}{*}{ Other approaches } & 2.8 & HCPs & $\begin{array}{l}\text { "In this case [by using a direct contact approach] the right not to know and the right on privacy } \\
\text { come into play. In addition, there are practical disadvantages, for example regarding how } \\
\text { relatives will be contacted without contact details. On the other hand, it [informed relatives] is of } \\
\text { great importance and proactive policy desired. A dilemma." (H3FG2, cardiologist, male) }\end{array}$ \\
\hline & 2.9 & Counselees & $\begin{array}{l}\text { "If a relative signs up, then it would be good to examine how that family is structured and } \\
\text { whether they are able to inform each other. Will that work well and will all the wishes of the } \\
\text { individuals be taken into account? Y'know, because that can already be messy, like I just said, } \\
\text { and before you know... So you have to consider, yeah, guys, what is more important, a person's } \\
\text { need for privacy, or the risk that they would be taking if they didn't know. So that might need to } \\
\text { be tailored [to the family], I'm afraid." (GIFL, relative, male, } 57 \text { years) }\end{array}$ \\
\hline & 2.10 & HCPs & $\begin{array}{l}\text { "I always discuss during the counselling with the proband who should approach family } \\
\text { members: the proband or us (the geneticists). ... Most probands want to approach their family } \\
\text { themselves, a small number want to do it jointly (for example telling their children themselves, } \\
\text { but having us tell their siblings) and an even smaller number want us to do all of it. I get the } \\
\text { impression that the probands like to have the choice, but I have never specifically asked." } \\
\text { (H7FG2, clinical geneticist, female) }\end{array}$ \\
\hline & 2.11 & Counselees & $\begin{array}{l}\text { "I'm not such a big supporter of different approaches. I foresee creating turmoil with people who } \\
\text { have received a family letter but then hear that someone else was contacted directly by the } \\
\text { hospital. On the other side is the danger that a family letter would be taken less seriously if } \\
\text { people saw that others were informed in person." (H12FGl, genetic counsellor, female) }\end{array}$ \\
\hline & 2.12 & HCPs & $\begin{array}{l}\text { "I think it is good to discuss everything with the doctors. [Follow-up] conversations should take } \\
\text { place on 'O, how did it [informing at-risk relatives] go and can we do anything for you, or } \\
\text { not?'." (U14IP, proband, female, } 64 \text { years })\end{array}$ \\
\hline
\end{tabular}

because of being ill themselves. Counselees also mentioned a psychological burden because of being the messenger of bad news and worrying about relatives' reactions. One relative described that the proband in his family delayed disclosing the information to relatives because he wanted to prevent his relatives worrying (Table 2, quote 2.3). Several HCPs also perceived it as a disadvantage to be dependent on probands for informing relatives, for example, in case of family conflicts. They, especially clinical geneticists and genetic counsellors, mentioned that the number of relatives who are informed and attend counselling is often unclear (Table 2, quote 2.4). Furthermore, counselees, probands, and relatives, noted that when relatives decide not to get tested, these relatives may refrain from informing their children about the genetic risks, thus not enabling them to make an individual decision regarding predictive DNA testing.

Active approach Using a direct contact approach, defined as HCPs directly contacting relatives about their genetic risks, was considered a reasonable alternative by both HCPs and counselees. Benefits of a direct contact approach mentioned by both HCPs and counselees were considered to be that more relatives are supposedly informed, that the quality of the information at first contact is improved, and that relatives would consider the information more important or urgent (Table 2, quote 2.5). Although the majority of participants felt that relatives are ideally informed by someone from their family, direct contact was considered appropriate only in exceptional cases by some. For example, if a proband has no contact with relatives, or when probands are unable or unwilling to inform. Some participants, both HCPs and counselees, considered direct contact more acceptable when preventive or treatment options are available (Table 2, quote 2.6). One relative believed direct contact should only be used in diseases with a severe phenotype and high penetrance.

Many participants, both HCPs and counselees, also perceived barriers to using a direct contact approach. Relatives might feel coerced to undergo genetic testing, and direct contact might cause more worry in at-risk relatives compared with a family-mediated approach (Table 2, quote 2.7). In addition, participants, especially cardiologists and genetic counsellors, mentioned practical barriers, such as an increased workload and (still) being dependent on probands for relatives' contact details. It was also mentioned by both HCPs and counselees that HCPs are unaware of personal circumstances of relatives and thus do not know whether it is the right moment to inform them. Some counselees mentioned that HCPs often use complex medical terms and that, in case of direct contact, information conveyed by HCPs could therefore be hard to understand. Some of the participants, both HCPs and counselees, also mentioned concerns regarding legal and ethical issues when using a direct contact approach, for example, preserving the right not to know, the right to privacy, and the possibility for relatives to make an autonomous decision (Table 2, quote 2.8). In addition, it 
was unclear for HCPs whether they were allowed to contact relatives directly. A few of them, however, felt the familymediated approach and a direct contact approach did not differ regarding the right not to know and the possibility for relatives to decide autonomously about predictive DNA testing. In addition, some HCPs and counselees believed that direct contact by HCPs was justified because of the availability of preventive and treatment options in ICCs.

Other approaches Some counselees believed the approach used should be dependent on the family and personality characteristics of the proband and his or her relatives, and thus the approach may be variable according to these characteristics (Table 2, quote 2.9). A majority of counselees were of the opinion that probands should always be asked whether they are able to and feel confident about informing relatives at risk, and what their preferences are. One HCP already used such an approach (Table 2, quote 2.10). However, many HCPs thought the approach used to inform relatives should be uniform, because using different approaches in one family could complicate the information process, introduce misinterpretations, and potentially distress relatives, and that it would be hard for counselees to make a decision regarding by whom and how they prefer relatives to be informed (Table 2, quote 2.11). In addition, HCPs mentioned practical barriers such as using different family letters for different relatives within one family.

HCPs thought the approach used to inform relatives at risk could be improved by having follow-up contact with counselees to evaluate the information process and to offer support in informing relatives if needed. A few counselees also mentioned that they preferred to have follow-up contact with the genetic counsellor or clinical geneticist (Table 2, quote 2.12). Some of the HCPs questioned whether genetic counsellors would have time to have these follow-up contacts with patients. Some HCPs also thought cardiogenetics clinics should create an overview of which relatives were informed and which relatives had attended genetic counselling.

\section{How should relatives at risk be informed?}

Table 3 shows themes and subthemes regarding how, according to counselees and HCPs, relatives at risk of ICCs should be informed.

There was a general preference for providing information in a stepwise manner to respect the right not to know and to not overload relatives with information (Table 3, quote 1.1). In the family-mediated approach, counselees preferred to inform and be informed in a face-to-face manner because this was considered the most personal approach. Counselees generally preferred to receive additional information from HCPs for relatives (Table 3, quote 1.2). A letter, either on paper or via e-mail, was considered the most suitable for providing additional information in case of a familymediated approach. The perceived benefits of a family letter were reported to be that it is professional and that it makes it possible for relatives to read it at an appropriate time (Table 3, quote 1.3). In addition, an official letter by the genetic counsellor correctly informs the general practitioner about the hereditary disease identified in the family and therefore helps in getting a referral for genetic counselling. When using a direct contact approach, some counselees also considered a letter or e-mail most appropriate,

Table 3 Themes and illustrative quotes from counselees and HCPs regarding how relatives at risk of inherited cardiac conditions should be informed

\begin{tabular}{|c|c|c|c|}
\hline Themes and subthemes & No. & Participants & Quotes \\
\hline \multicolumn{4}{|c|}{ Information provided to probands and relatives } \\
\hline $\begin{array}{l}\text { Stepwise information } \\
\text { provision }\end{array}$ & 1.1 & HCPs & $\begin{array}{l}\text { "I would begin with summary information (diagnosis and personal risk chance) and through } \\
\text { links let the patient choose the tempo and how much information they would like to receive." } \\
\text { (H9FG1, clinical geneticist, male) }\end{array}$ \\
\hline Information provision & 1.2 & Counselees & $\begin{array}{l}\text { "I think you can possibly help best by sharing an experience or like I've once seen a patient... } \\
\text { he told it in this way, or that way... And just give as much information as possible, like the } \\
\text { letter that's ready and waiting for us to take to our GP right away. I found that reasonably done. } \\
\text { That gave me, yeah, as we used to say, enough information to make a final decision [about } \\
\text { predictive DNA testing] and to choose to take part." (U13FL, relative, } 31 \text { years) }\end{array}$ \\
\hline \multirow[t]{2}{*}{$\begin{array}{l}\text { Medium to provide } \\
\text { information }\end{array}$} & 1.3 & Counselees & $\begin{array}{l}\text { "No, I think the letter is actually okay. Yes. Yes, if I compare it to a telephone call, when I } \\
\text { think people panic, and, eh.., I think they get so overwhelmed they stop hearing what's being } \\
\text { said. And a letter you can read again, and you can do that as often as you want. With a } \\
\text { telephone call I think that when people hang up they suddenly think, 'Woah. What now? } \\
\text { What did I just hear, actually?' And they can't get any further with that." (U1FL, relative, } \\
\text { female, } 54 \text { years) }\end{array}$ \\
\hline & 1.4 & HCPs & $\begin{array}{l}\text { "That's [a website] definitely very modern, so I think it's an acceptable option. I do think that } \\
\text { relatives need to have a personal account to protect the privacy of the family and their personal } \\
\text { information." (H12FG2, genetic counsellor, female) }\end{array}$ \\
\hline
\end{tabular}


but others preferred telephone contact so that relatives could immediately get answers to their questions. This may, however, also upset relatives. Websites were considered appropriate for providing additional information to relatives, if desired. When using a login code and a secured network, some participants believed websites could also be used for informing relatives personally, thereby making it more easily accessible (Table 3 , quote 1.4 ).

\section{Discussion}

This qualitative study explored the attitudes of HCPs and counselees toward informing relatives at risk of ICCs. Both HCPs and counselees seemed to be in favour of someone from the family informing at-risk relatives. However, this family-mediated approach was, for many, only preferred in case of good family relationships.

To inform relatives sufficiently, additional information provided by HCPs was considered essential, especially in the family-mediated approach. As pointed out by Dheensa et al. [20], information provision by HCPs supports probands in informing relatives and facilitates relatives' decision-making regarding predictive DNA testing and their communication with their general practitioner for referral. Technological innovations, such as secured websites, could facilitate the provision of and access to information, and were considered acceptable by many participants [17].

Our results indicate that many participants had a positive attitude toward a more active role of HCPs, primarily in case of barriers that hamper informing at-risk relatives. However, some participants, especially HCPs, believed that mandating that HCPs inform relatives directly may impose an unfeasible responsibility on HCPs with regard to time and expense [25]. In addition, participants believed that direct contact approaches would breach the right not to know and patient confidentiality [25-27]. Some participants, however, believed that direct contact by HCPs would be justified since preventive and treatment options are available in ICCs, as suggested by previous research $[15,26]$.

Although attitudes of HCPs and counselees participating in this study generally corresponded, attitudes of HCPs and counselees seemed to differ with regarding to tailoring the approach to individual and family characteristics. Most counselees believed that individual and family characteristics should be taken into account when deciding upon the approach. Varying the approach according to these characteristics and the preferences of counselees may increase the number of relatives enabled to make an informed decision regarding predictive DNA testing [25, 28]. However, many HCPs believed that use of different approaches within one family could confuse relatives. Furthermore, due to limited resources, the majority of HCPs preferred uniformity in procedures. However, one could imagine a uniform approach tailored to probands' preferences and family and individual characteristics, with (1) probands informing relatives themselves supported by a family letter in case of good family relationships, and (2) HCPs directly contacting relatives (a) in case of family conflicts or (b) in case the first approach appeared not to be effective at follow-up. Further research, particularly randomized controlled trials, is needed to assess such more active approaches.

This study was conducted in the context of ICCs. Our findings indicate that the availability of prevention and treatment options influences attitudes and preferences of HCPs and counselees, i.e., more active approaches are justified because of the possibility of prevention or of treating symptoms of the disease. To our knowledge, the number of studies on preferences regarding informing atrisk relatives performed in ICCs is still limited [21, 29, 30]. A review by Shah et al. [31] suggested that attitudes of patients with ICCs toward family communication might be influenced by the young age of onset and the risk of sudden cardiac death. Previous research on preferences in hereditary types of cancer in which prevention and treatment is possible, indicates similar attitudes to those seen in our study, suggesting that specific characteristics of ICCs might not cause different attitudes to informing at-risk relatives [5, 22, 32-34].

This multicentre study allowed for a comparison between perspectives of HCPs and counselees. In addition, a multidisciplinary sample of HCPs from all cardiogenetics clinics in the Netherlands participated in this study. A study limitation was the low response rate among counselees, possibly a consequence of the qualitative set-up of the study, initially planned as a focus group study, later transformed into individual interviews because people did not want to share their personal family experiences. Besides, more female than male participants participated, which suggests a response bias. Participants experiencing difficulties in informing relatives at risk were possibly more inclined to participate, thereby inducing a response bias as well. Experiences of participants may also have been subject to recall bias, although only those who were counselled in the year prior to the study were approached to participate. Furthermore, since the majority of both HCPs and counselees in this study were only familiar with the familymediated approach, they were asked to imagine how they would experience other more active approaches. Finally, counselees were counselled by different counsellors in three centres in total. Although approaches used in these centres were similar, this may have influenced our findings and our findings may therefore not be generalizable to other centres. 


\section{Conclusions}

This study suggests that individuals facing ICC, and their HCPs, generally prefer a family-mediated approach to informing at-risk relatives. Nevertheless, HCPs, probands and relatives considered direct contact a reasonable addition when family barriers are present. Counselees believed that the approach used to inform at-risk relatives should ideally be tailored to patient- and family characteristics, but HCPs preferred uniformity in procedures due to high workload. A uniform approach tailored to family characteristics is suggested, with HCPs directly contacting relatives in case of family conflicts or in case the family-mediated approach appeared not to be effective at follow-up. Further research is warranted on how to engage HCPs more actively in informing at-risk relatives in current clinical genetic practise.

Acknowledgements We thank the experts on legal and ethical issues and members of patient organizations for sharing their perspectives and their reflection on our findings. We also thank Kate McIntyre for editing the manuscript. We acknowledge the support from the Netherlands Cardiovascular Research Initiative: An initiative with support of the Dutch Heart Foundation (CVON 2015-12 eDETECT).

\section{Compliance with ethical standards}

Conflict of interest The authors declare that they have no conflict of interest.

Publisher's note: Springer Nature remains neutral with regard to jurisdictional claims in published maps and institutional affiliations.

\section{References}

1. Maron BJ. Risk stratification and role of implantable defibrillators for prevention of sudden death in patients with hypertrophic cardiomyopathy. Circ J. 2010;74:2271-82.

2. Priori SG, Wilde AA, Horie M, Cho Y, Behr ER, Berul C, et al. HRS/EHRA/APHRS expert consensus statement on the diagnosis and management of patients with inherited primary arrhythmia syndromes: document endorsed by HRS, EHRA, and APHRS in May 2013 and by ACCF, AHA, PACES, and AEPC in June 2013. Heart Rhythm. 2013;10:1932-63.

3. Behr ER, Dalageorgou C, Christiansen M, Syrris P, Hughes S, Tome Esteban MT, et al. Sudden arrhythmic death syndrome: familial evaluation identifies inheritable heart disease in the majority of families. Eur Heart J. 2008;29:1670-80.

4. Miller EM, Wang Y, Ware SM. Uptake of cardiac screening and genetic testing among hypertrophic and dilated cardiomyopathy families. J Genet Couns. 2013;22:258-67.

5. Leenen $\mathrm{CH}$, Heijer M, van der Meer C, Kuipers EJ, van Leerdam ME, Wagner A. Genetic testing for Lynch syndrome: family communication and motivation. Fam Cancer. 2016;15:63-73.

6. Christiaans I, Birnie E, Bonsel GJ, Wilde AA, van Langen IM. Uptake of genetic counselling and predictive DNA testing in hypertrophic cardiomyopathy. Eur J Hum Genet. 2008;16: 1201-7.

7. Van der Roest WP, Pennings JM, Bakker M, van den Berg MP, van Tintelen JP. Family letters are an effective way to inform relatives about inherited cardiac disease. Am J Med Genet A. 2009;149A:357-63.

8. Burns C, McGaughran J, Davis A, Semsarian C, Ingles J. Factors influencing uptake of familial long QT syndrome genetic testing. Am J Med Genet A. 2016;170A:418-25.

9. Clarke A, Richards M, Kerzin-Storrar L, Halliday J, Young MA, Simpson SA, et al. Genetic professionals' reports of nondisclosure of genetic risk information within families. Eur J Hum Genet. 2005; $13: 556-62$.

10. Falk MJ, Dugan RB, O'Riordan MA, Matthews AL, Robin NH. Medical Geneticists' duty to warn at-risk relatives for genetic disease. Am J Med Genet A. 2003;120A:374-80.

11. Forrest LE, Burke J, Bacic S, Amor DJ. Increased genetic counseling support improves communication of genetic information in families. Genet Med. 2008;10:167-72.

12. Hodgson JM, Metcalfe S, Gaff C, Donath S, Delatycki MB, Winship I, et al. Outcomes of a randomised controlled trial of a complex genetic counselling intervention to improve family communication. Eur J Hum Genet. 2016;24:356-60.

13. Aktan-Collan K, Haukkala A, Pylvanainen K, Jarvinen HJ, Aaltonen LA, Peltomaki P, et al. Direct contact in inviting high-risk members of hereditary colon cancer families to genetic counselling and DNA testing. J Med Genet. 2007;44:732-8.

14. Menko FH, Ter Stege JA, van der Kolk LE, Jeanson KN, Schats W, Moha DA, et al. The uptake of presymptomatic genetic testing in hereditary breast-ovarian cancer and Lynch syndrome: a systematic review of the literature and implications for clinical practice. Fam Cancer. 2019;18:127-35.

15. Sermijn E, Delesie L, Deschepper E, Pauwels I, Bonduelle M, Teugels E, et al. The impact of an interventional counselling procedure in families with a BRCA1/2 gene mutation: efficacy and safety. Fam Cancer. 2016;15:155-62.

16. Suthers GK, Armstrong J, McCormack J, Trott D. Letting the family know: balancing ethics and effectiveness when notifying relatives about genetic testing for a familial disorder. J Med Genet. 2006;43:665-70.

17. Sturm AC. Cardiovascular cascade genetic testing: exploring the role of direct contact and technology. Front Cardiovasc Med. 2016;3:11.

18. Dheensa S, Fenwick A, Shkedi-Rafid S, Crawford G, Lucassen A. Health-care professionals' responsibility to patients' relatives in genetic medicine: a systematic review and synthesis of empirical research. Genet Med. 2016;18:290-301.

19. Kitzinger J. Qualitative research. Introducing focus group. BMJ. 1995;311:299-302.

20. Dheensa S, Lucassen A, Fenwick A. Limitations and pitfalls of using family letters to communicate genetic risk: a qualitative study with patients and healthcare professionals. J Genet Couns. 2018;27:689-701.

21. Ormondroyd E, Oates S, Parker M, Blair E, Watkins H. Pre-symptomatic genetic testing for inherited cardiac conditions: a qualitative exploration of psychosocial and ethical implications. Eur J Hum Genet. 2014;22:88-93.

22. Ratnayake P, Wakefield CE, Meiser B, Suthers G, Price MA, Duffy $\mathrm{J}$, et al. An exploration of the communication preferences regarding genetic testing in individuals from families with identified breast/ ovarian cancer mutations. Fam Cancer. 2011;10:97-105.

23. VERBI Software. MAXQDA 2018. Berlin (Germany): VERBI software; 2017.

24. Braun V, Clarke V. Using thematic analysis in psychology. Qual Res Psychol. 2006;3:77-101.

25. Weaver M. The double helix: applying an ethic of care to the duty to warn genetic relatives of genetic information. Bioethics . 2016;30:181-7.

26. Newson AJ, Humphries SE. Cascade testing in familial hypercholesterolaemia: how should family members be contacted? Eur J Hum Genet. 2005;13:401-8. 
27. Stol YH, Menko FH, Westerman MJ, Janssens RM. Informing family members about a hereditary predisposition to cancer: attitudes and practices among clinical geneticists. J Med Ethics. 2010;36:391-5.

28. Leonard SJ, Newson, AJ. Ethical perspectives. In: Gaff CL, Bylund, CL, editors. Family communication about genetics: theory and practice. New York: Oxford University Press, Inc.; 2010.

29. Vavolizza RD, Kalia I, Erskine Aaron K, Silverstein LB, Barlevy D, Wasserman D, et al. Disclosing genetic information to family members about inherited cardiac arrhythmias: an obligation or a choice? J Genet Couns. 2015;24:608-15.

30. Whyte S, Green A, McAllister M, Shipman H. Family communication in inherited cardiovascular conditions in Ireland. J Gen Couns. 2016;25:1317-26.
31. Shah LL, Daack-Hirsch S. Family communication about genetic risk of hereditary cardiomyopathies and arrhythmias: an integrative review. J Genet Couns. 2018;27:1022-39.

32. Dilzell K, Kingham K, Ormond K, Ladabaum U. Evaluating the utilization of educational materials in communicating about Lynch syndrome to at-risk relatives. Fam Cancer. 2014;13:381-9.

33. Forrest LE, Curnow L, Delatycki MB, Skene L, Aitken M. Health first, genetics second: exploring families' experiences of communicating genetic information. Eur J Hum Genet. 2008;16: 1329-35.

34. Menko FH, Aalfs CM, Henneman L, Stol Y, Wijdenes M, Otten E, et al. Informing family members of individuals with Lynch syndrome: a guideline for clinical geneticists. Fam Cancer. 2013;12:319-24. 